\title{
La Pirekua como Patrimonio Cultural Inmaterial de la Humanidad. Efectos del nuevo paradigma patrimonial, de Georgina Flores Mercado
}

\author{
The Pirekua as Cultural Intangible Heritage of the Humanity. Effects of \\ the new heritage paradigm, by Georgina Flores Mercado
}

\author{
Federico Zúñiga-Bravo
}

Dirección de Etnología y Antropología Social, Instituto Nacional de Antropología e Historia, México

*Autor a quien se dirige la correspondencia: federico_zuniga@inah.gob.mx

GEORGINA FLORES MERCADO

\section{ㅁํㅁำㅁำ}

La

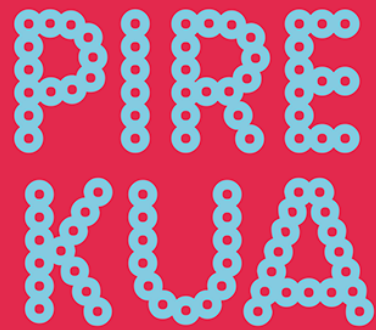

como Patrimonio Cultural Inmaterial de la Humanidad

Efectos del nuevo paradigma patrimonial

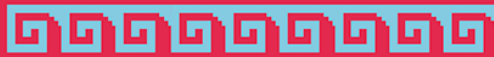

Universidad Nacional Autónoma de México Instituto de Investigaciones Sociales
¿Qué se necesita para que una práctica o bien cultural, en este caso, sea inscrito en las Listas Representativas del Patrimonio Cultural Inmaterial de la Humanidad de la Unesco? Ante esta interrogante, lo primero que se puede pensar es que la producción y reproducción de dicha práctica o bien se encuentre en riesgo, lo que implica que se considere su inclusión en estas listas.

De acuerdo con la Convención para la Salvaguardia del Patrimonio Inmaterial, aprobada por la Conferencia General de la Organización de las Naciones Unidas para la Educación, la Ciencia y la Cultura (Unesco, siglas en ingles) en el año 2003 — cuyo objetivo principal es salvaguardar los usos, representaciones, expresiones, conocimientos y técnicas que las comunidades, los grupos y, en algunos casos, los individuos reconocen como parte integrante de su patrimonio cultural - el principal propósito de esta convención es dar a conocer mejor el patrimonio cultural en todo el mundo. Para ello, la estrategia adecuada para lograrlo es la "salvaguardia", la cual es definida por el propio organismo internacional como las medidas encaminadas a garantizar la viabilidad del patrimonio cultural inmaterial a través de la identificación, documentación, investigación, preservación, protección, promoción, valoración, transmisión y revitalización de este patrimonio en sus diferentes aspectos (Unesco, 2003). 
Sin embargo, la definición anterior nos lleva a otro cuestionamiento: ¿salvaguardar para quién y con qué fines? Si se analiza el término "salvaguardia", como es explicado líneas arriba, merece la pena destacar los verbos "promoción" y "valoración", si se considera que se pueden prestar a diferentes interpretaciones. Así, una vez que aquellas prácticas y bienes culturales han sido seleccionados y valorizados como "patrimonio", adquieren un aura de notoriedad, son visibilizados y promovidos como algo auténtico, excepcional y atractivo, tras la adquisición de nuevos valores (valor de cambio y valor de uso). De esta forma, mediante estrategias de marketing (cultural y turístico) el patrimonio se transforma en objeto de deseo y consumo para diversos nichos del mercado capitalista, destacando entre estos el del turismo y las industrias culturales.

En este sentido, la interpretación y análisis que se hace de la patrimonialización como medida de salvaguardia para ciertas expresiones culturales, pero también en su relación con el capitalismo, se debe al protagonismo que el patrimonio cultural, en su carácter material o inmaterial, ha adquirido en el ámbito sociopolítico, económico y en el de las políticas públicas globales, al ser visto como un recurso explotable a través de su puesta en valor. De ahí que, en los últimos años, los cuestionamientos hacia la Unesco se deben a que su papel como institución legitimadora del patrimonio se ha orientado principalmente a su cercanía con las industrias culturales y el turismo, ya que, para dicho organismo, el patrimonio puede ser utilizado como una estrategia de desarrollo sustentable (Unesco, 2003).

La acción de patrimonializar consistiría en evaluar, declarar, normar y legislar sobre un bien considerado patrimonial, reconociendo que debe ser protegido y conservado para las presentes y futuras generaciones. No obstante, la patrimonialización puede igualmente ser concebida como la base sobre la que descansan diversas formas de mercantilización de lo auténtico en el ámbito de la cultura y la naturaleza, como bien apunta Frigolé (2014). Es un patrimonio que se pone a disposición de un público que trasciende las fronteras nacionales con otra narrativa. Por tanto, al cambiar de estatus cambia de valor, se modifica de manera considerable, trayendo consigo nuevas operatividades del patrimonio, nuevos usos sociales, aunque también produce una cosificación de los actores sociales poseedores de este patrimonio.

En este sentido, La Pirekua como Patrimonio Cultural Inmaterial de la Humanidad. Efectos del nuevo paradigma patrimonial, obra de la Dra. Georgina Flores Mercado (Instituto de Investigaciones Sociales-Universidad Nacional Autónoma de México, 2017), es una relevante aportación a los estudios sobre el patrimonio musical de México al focalizar su investigación en el proceso de patrimonialización de la pirekua, expresión de la cultura musical del pueblo p'urhépecha del estado de Michoacán, México - la cual fue declarada por la Unesco en noviembre de 2010, junto con la cocina tradicional y la danza de los parachicos, como Patrimonio Cultural Inmaterial de la Humanidad - que, como bien señala, el objetivo principal de este trabajo es el de dar cuenta de dicho proceso desde una perspectiva social y crítica en el marco de una nueva etapa de las políticas culturales nacionales e internacionales.

Como ha referido la propia autora en otras publicaciones, a partir de que la industria turística en el estado Michoacán ha cobrado suma importancia para el desarrollo económico de la entidad, esto ha generado un nuevo campo de relaciones entre instituciones, empresas y pueblos indígenas. En el caso de las comunidades p'urhépechas, lo enunciado en líneas anteriores destaca debido a que estas han sido consideradas como potenciales nichos de mercado para el turismo cultural: su entorno geográfico, sus sitios arqueológicos, su arquitectura vernácula y religiosa, su artesanía, sus fiestas, su gastronomía, sus danzas y su música (Flores, Nava, \& Reynoso, 2016, p. 31). Por tanto, la patrimonialización y turistificación de la pirekua, como una de las diversas expresiones de las culturas musicales de los p'urhepechas, se vuelve su principal objeto de análisis en esta reciente publicación.

Los cuatro capítulos que conforman la mencionada obra, son producto de una minuciosa investigación sustentada no sólo en la revisión bibliográfica, hemerográfica y documental que se puede apreciar con detalle en la introducción del libro y el capítulo 1: El expediente de candidatura: protagonismos políticos y exclusión social, sino también en las continuas y extensas temporadas de trabajo campo en varias de las comunidades existentes en las regiones geográfico-culturales que conforman al Estado de Michoacán: región lacustre, meseta $\mathrm{P}^{\prime}$ urhépecha y cañada de los Once Pueblos, aunado a la interacción con los principales portadores de la tradición musical - los pireris, los cantores, y músicos- que, más allá de la realización de la aplicación de encuestas y entrevistas a profundidad para recoger información relevante sobre el tema de estudio, emergió un sentido de soli- 
daridad y acompañamiento a sus demandas a través del análisis del Movimiento Pireri, del cual nos habla en el capítulo 2: El Movimiento Pireri. La respuesta colectiva organizada. Cuyo objetivo fue reflexionar e informarse sobre los efectos de la patrimonialización de la pirekua, dando origen a dicho movimiento como acción de inconformidad y oposición, debido a que no se consideró el derecho a la consulta para la mayoría de los implicados, como estipula el Convenio 169 de la Organización Internacional del Trabajo. A su vez, la profundidad del análisis y registro etnográfico se ve reflejado en los capítulos 3: A cinco años de la declaratoria. Discursos y acciones institucionales, y 4: La turistificación de la pirekua. Política cultural neoliberal y cultura p'urhépecha. En ambos capítulos, el papel y los discursos de los actores institucionales -mediante la puesta en marcha de acciones para la, supuesta, salvaguardia de la pirekua como parte de los primeros cinco años de la trayectoria emprendida tras su declaratoria - se opone y resulta en una contradicción con la turistificación de otras expresiones de la cultura p'urhepecha, en la que está incluida la pirekua trayendo consigo una serie de resignificaciones y recontextualizaciones a través de su puesta en valor para consumo turístico, a la par de cosificar a los productores de cultura, los actores comunitarios, como un referente de atractivo y mercancía étnica.

Esta obra de la Dra. Georgina Flores Mercado no sólo amplía los estudios sobre el patrimonio musical de México, sino que contribuye, por un lado, a profundizar en el análisis de la tradición musical de la pirekua, si se considera la escasez de trabajos salvo contadas excepciones - como la publicación de Pirekua. Canto poco conocido, coordinada por Márquez (2010) y editado por el Colegio de Michoacán - mientras que, por el otro, invita a reflexionar sobre la cada vez más estrecha relación entre músicas y tradicionales y turismo, lo que da continuidad a sus investigaciones anteriores, haciendo de su trabajo una referencia obligada en el tema.

Hoy en día que la moda institucional por las denominaciones patrimoniales de la Unesco contrasta con la demanda de los pueblos y comunidades por evitar la desaparición de su diversidad cultural (Alcántara, 2011), lo que implica preguntarse para quién se salvaguarda, y ante la expansión de lo patrimonial que responde a la racionalidad de la economía neoliberal, en este caso a través del turismo global, Georgina Flores Mercado hace una aportación relevante con esta publicación para seguir reflexionando y cuestionando si la patrimonialización y el papel de la Unesco como una institución que monopoliza el sello legitimador de patrimonio cultural y gestiona el nomenclátor a nivel mundial en estos procesos de patrimonialización, conlleva incluir a otros actores - Estados nacionales, comunidades locales, políticos, empresarios, gestores y promotores culturales - interesados en apostar por el turismo como un mecanismo que facilita la conversión de la cultura y el patrimonio en un elemento viable de constituirse en mercancía. El caso de la pirekua, expuesto por esta autora, es el mejor ejemplo.

\section{Referencias}

Alcántara, A. (julio-septiembre, 2011). ¿Salvaguardar para quién? Memorias, prácticas y discursos. En Diario de Campo, (5), 21-29.

Flores, G., Nava, F., \& Reynoso, C. (2016). Esto es música p'urhépecha... Pireris, pirekuas y turismo en Michoacán. En G. Flores-Mercado \& F. Nava (Coords.), Identidades en venta. Músicas tradicionales y turismo en México (pp. 31-67). México: Universidad Nacional Autónoma de México, Instituto de Investigaciones Sociales.

Frigolé, J. (2014). Retóricas de la autenticidad en el capitalismo avanzado. Éndoxa, (33), 37-60.

Márquez, P. (Comp.). (2010). Pirekua, canto poco conocido. Zamora, Michoacán, México: El Colegio de Michoacán, Uantap'erakua, Consejo para el Arte y la Cultura de la Región P'urhepecha

Organización de las Naciones Unidas para la Educación, la Ciencia y la Cultura (2003). Convención para la Salvaguardia del Patrimonio Cultural Inmaterial. París: Autor. Recuperado de https:// unesdoc.unesco.org/ ark:/48223/pf0000132540_ spa

\section{Datos editoriales del libro}

Autora: Georgina Flores Mercado

Título: La Pirekua como Patrimonio Cultural Inmaterial de la Humanidad. Efectos del nuevo paradigma patrimonial Lugar y año de publicación: México, 2017

Casa editora: Universidad Nacional Autónoma de México, Instituto de Investigaciones Sociales ISBN: 978-607-02-9546-1 